\title{
Healthy and unhealthy dietary patterns are related to pre-diabetes: a case-control study
}

\author{
Fariba Bagheri ${ }^{1}$, Fereydoun Siassi ${ }^{1 *}$, Fariba Koohdani $^{2}$, Behzad Mahaki ${ }^{3}$, Mostafa Qorbani ${ }^{4}$, \\ Parvaneh Yavari ${ }^{1}$, Osman Mohammed Shaibu ${ }^{1}$ and Gity Sotoudeh ${ }^{1 *}$ \\ ${ }^{1}$ Department of Community Nutrition, School of Nutritional Sciences and Dietetics, Tehran University of Medical Sciences, \\ Hojatdost Street, Naderi Street, Keshavarz Blv., 14155/6117, Tebran, Iran \\ ${ }^{2}$ Department of Cellular and Molecular Nutrition, School of Nutritional Sciences and Dietetics, Tebran University of Medical \\ Sciences, Hojatdost Street, Naderi Street, Keshavarz Blv., 14155/6117, Tehran, Iran \\ ${ }^{3}$ Department of Epidemiology and Biostatistics, School of Public Health, Isfahan University of Medical Sciences, Hezarjarib \\ Street, 81746-73461, Isfahan, Iran \\ ${ }^{4}$ Department of Community Medicine, School of Medicine, Alborz University of Medical Sciences, 3146883411, Karaj, Iran \\ (Submitted 23 December 2015 - Final revision received 26 May 2016 - Accepted 2 June 2016 - First published online 25 July 2016)
}

\section{Abstract}

Pre-diabetes increases the risk of diabetes and CVD. Several studies have investigated the relationship between food intake and pre-diabetes morbidity, but the dietary patterns of pre-diabetes subjects were not taken into consideration. The aim of this study was to determine the relationship between dietary patterns and pre-diabetes. In this regard, 150 pre-diabetic subjects and 150 healthy controls, who attended the diabetes screening centre in Shahreza, Iran, were matched for age group and sex. The weight, height, waist circumference, physical activity, systolic and diastolic blood pressures, and blood glucose levels of all participants were measured. Dietary information was collected using a semi-quantitative FFQ. Using factor analysis, two dietary patterns were identified: the vegetables, fruits and legumes (VFL) dietary pattern and the sweet, solid fat, meat and mayonnaise (SSMM) dietary pattern. Multivariate logistic regression was used to assess the relationship between pre-diabetes and dietary patterns. After adjusting for age, education, physical activity, BMI and energy intake, the VFL dietary pattern was found to be negatively associated with lower pre-diabetes (OR $0 \cdot 16 ; 95 \%$ CI $0 \cdot 10,0 \cdot 26$ ). Furthermore, the SSMM dietary pattern was positively associated with pre-diabetes (OR 5.45; $95 \%$ CI 3.22, 9.23). In conclusion, the VFL dietary pattern is inversely related to pre-diabetes, whereas the SSMM dietary pattern is associated with increased risk of pre-diabetes.

\section{Key words: Pre-diabetes: Dietary patterns: Factor analyses}

Pre-diabetes is a condition of abnormal glucose homoeostasis such as impaired fasting glucose, impaired glucose tolerance (IGT) or a combination of both ${ }^{(1)}$. This disorder is diagnosed by the fasting blood glucose (FBG) test with values between 5.6 and $6.9 \mathrm{mmol} / \mathrm{l}$ being regarded as pre-diabetic or by the 2 -h oral glucose tolerance test (OGTT) with values between 7.8 and $11 \mathrm{mmol} / \mathrm{l}$ or glycosylated $\mathrm{Hb}$ (HbA1c) of $5.7-6.4 \%$ being regarded as pre-diabetic ${ }^{(2)}$. Pre-diabetes is associated with lack of physical activity, abdominal obesity, dyslipidaemia and hypertension, and can lead to the development of insulin resistance, diabetes, chronic kidney disease and $\mathrm{CVD}^{(3-5)}$. The prevalence of pre-diabetes has been reported to be $28.7 \%$ based on FBG and $12.4 \%$ based on HbA1c in the $\mathrm{USA}^{(6)}$. In 2008, about $7.7 \%$ of the Iranian population was diagnosed with diabetes, and $16.8 \%$ was diagnosed with pre-diabetes by the FBG test ${ }^{(7)}$. In the past few decades, the prevalence and incidence of type 2 diabetes have increased, and the disease has therefore become an epidemic around the world. In Asia, the rate of increase shows no sign of slowing down ${ }^{(8,9)}$. It has been reported that diabetes can be prevented through lifestyle modification in individuals who are at high risk of type 2 diabetes ${ }^{(10,11)}$. Western lifestyle, characterised by reduced physical activity and consumption of foods rich in SFA, refined grains and red meat, has been reported to increase the risk of diabetes ${ }^{(12)}$. Identifying dietary patterns and finding their relationship with chronic diseases is better than studying the relationships between nutrients and diseases; this is because people do not make use of the concept of nutrients and food separately. In addition, the nutrients of different foods may have synergistic or interactive effects on each other and it is easier to educate subjects on dietary patterns ${ }^{(13)}$. Most available studies have examined the relationship between dietary patterns and diabetes $^{(14)}$, but studies investigating the associations between dietary patterns and pre-diabetes are limited ${ }^{(15,16)}$. Moreover, the increasing incidence of diabetes and unique patterns of food

Abbreviations: FBG, fasting blood glucose; IGT, impaired glucose tolerance; OGTT, oral glucose tolerance test; SSMM, sweet, solid fat, meat and mayonnaise; VFL, vegetables, fruits and legumes; WC, waist circumference.

* Corresponding authors: G. Sotoudeh, fax +98 218897 4462, email gsotodeh@tums.ac.ir; F. Siassi, fax +98 21 8897 4462, email siassif@tums.ac.ir 
consumption among the Iranian population ${ }^{(17)}$, therefore, make it interesting to assess the relationship between dietary patterns and pre-diabetes. Most previous studies in Iran have only reported the dietary patterns of healthy subjects ${ }^{(18,19)}$. However, a crosssectional study in one of the cities of Iran found an inverse association between vegetarian dietary patterns and IGT ${ }^{(17)}$. The aim of the present study was therefore to determine the relationship between dietary patterns and pre-diabetes using a matched case-control study design.

\section{Methods \\ Subjects}

A matched case-control study design was used to investigate 300 subjects, who attended the diabetes screening centre in Shahreza, Iran, from May to October, 2014. Subjects $>30$ years of age and who were at risk of diabetes morbidity based on the existence of at least one of the following criteria were referred to this centre: being overweight or obese, having a family history of diabetes or existence of at least two symptoms of diabetes. The diagnosis of pre-diabetes among subjects was made at the clinic. This study included 150 subjects who had been diagnosed with pre-diabetes (cases). After recruitment of all cases, 150 healthy subjects with normal FBG, considering other inclusion criteria, were recruited as the control group. Using the frequency matching method, the two groups were matched by age and sex. The groups matched for age were as follows: $35-44,45-54$ and 55-65 years; the two groups were also matched for sex. Inclusion criteria for the case group included subjects aged 35-65 years, FBG between 5.6 and $6.9 \mathrm{mmol} / \mathrm{l}$ or 2 -h OGTT of $7.8-11 \mathrm{mmol} / \mathrm{l}$, and diagnosis confirmed at least 3 months before the start of the study. Inclusion criteria for the control group included subjects aged 35-65 years, FBG $<5.6 \mathrm{mmol} / \mathrm{l}$ and 2 -h OGTT $<7.8 \mathrm{mmol} / \mathrm{l}$ during screening. However, subjects who were found and/or reported to be alcoholics, drug addicts (current use or stopped within 3 months before the study), smokers or used any tobacco products, such as a smoking of pipe at least once a week, were excluded from the study. Subjects with BMI $\geq 40$ $\mathrm{kg} / \mathrm{m}^{2}$, pregnant or lactating women, those on a special diet during the previous year, subjects with diagnosed heart disease, diabetes, hypertension, dyslipidaemia, renal or hepatic impairment and multiple sclerosis, and individuals on drugs were also excluded. Dietary supplement intake was defined as daily intake of supplements in the previous month. Written informed consent was obtained from all participants before commencement of the study. The study protocol was approved by the ethics committee of Tehran University of Medical Sciences.

\section{Assessment of anthropometry, blood pressure and physical activity}

Anthropometric measurements such as weight, height, waist circumference (WC), as well as systolic and diastolic blood pressure were obtained from all participants. Weight was measured to the nearest gram $(100 \mathrm{~g})$ without shoes and with minimal clothing using the Seca scale. Height was measured to the nearest $0 \cdot 1 \mathrm{~cm}$ while standing without shoes using the Seca stadiometer (Seca 216). WC was measured using a flexible tape at the midpoint between the lowest rib and the iliac crest hip. Systolic blood pressure and diastolic blood pressure were measured once in the left arm while sitting using a manual sphygmomanometer. The BMI of each participant was calculated by dividing the weight in kilograms by the square of height in metres. Abdominal obesity was defined as $\mathrm{WC} \geq 80 \mathrm{~cm}$ in women and $\mathrm{WC} \geq 90 \mathrm{~cm}$ in men ${ }^{(20)}$. General obesity was defined as $\mathrm{BMI} \geq 30 \mathrm{~kg} / \mathrm{m}^{2}$. Physical activity was assessed using the International Physical Activity Questionnaire (IPAQ) ${ }^{(21)}$. The information collected using IPAQ was categorised as 'low physical activity' (point score <600 metabolic equivalent (MET)/h per week), 'moderate physical activity' (point score between 600 and $3000 \mathrm{MET} / \mathrm{h}$ per week) and 'high physical activity' (point score $>3000 \mathrm{MET} / \mathrm{h}$ per week).

\section{Biochemical assessment}

Blood samples were collected after an overnight fast (at least $8 \mathrm{~h}$ ) for FBG measurement. The subjects underwent a 2-h OGTT. Venous blood was used, and plasma glucose was analysed at $546 \mathrm{~nm}$ wavelength using the photometric method (glucose oxidase method).

\section{Dietary assessment}

Dietary information was obtained by interview using a 168-item, semi-quantitative FFQ, which measured the previous year's food intake (for cases the year before diagnosis of pre-diabetes and for controls during the previous year). The participants were asked how often they consumed each food item of different categories: daily, weekly, monthly or yearly. Information obtained from the FFQ was converted to $\mathrm{g} / \mathrm{d}$ in order to estimate daily food intake. The validity and reliability of the FFQ used were tested ${ }^{(22)}$.

\section{Statistical methods}

Statistical analysis was performed using Statistical Package for Social Sciences, version 16 (SPSS Inc.). On the basis of the similarity of food items and previous studies ${ }^{(19,23)}$, twenty-seven food groups were created. A food item was categorised into an independent group if its nutrient content had a huge difference from other food items (such as eggs) or the consumption of such an item was a special food habit (such as pickles) (Table 1). Factor analysis was used to determine the dietary patterns of all participants ${ }^{(24)}$. In this study, principal component analysis with varimax rotation was used to determine the major dietary patterns, and then the factors were pre-selected to determine which set of factors meaningfully described the distinct dietary patterns. Factors with eigenvalues $\geq 1.8$ were chosen as the major dietary patterns. Thereafter, a factor score was calculated for each participant by summing the intakes of food groups, weighted by their factor loading. Factor loading represents the correlation between a dietary pattern and each food group. A larger absolute value indicates greater 
Table 1. Food grouping used in the factor analysis

\begin{tabular}{|c|c|}
\hline Food groups & Subgroups \\
\hline Vegetable & $\begin{array}{l}\text { Lettuce, cucumber, squash, eggplant, celery, green } \\
\text { peas, green beans, carrots, garlic, onions, all kinds } \\
\text { of cabbage, bell peppers, spinach, turnip, } \\
\text { mushrooms, green peppers, maize }\end{array}$ \\
\hline Legume & $\begin{array}{l}\text { Lentils, beans, peas, beans, soyabeans, mung } \\
\text { beans, split peas }\end{array}$ \\
\hline Dried fruit & Dried fruit \\
\hline Tomato & Tomato \\
\hline Fruits & All fruits and juice \\
\hline $\begin{array}{l}\text { Low-fat dairy } \\
\text { products }\end{array}$ & Low-fat milk, low-fat yogurt, cheese \\
\hline Chicken & Chicken \\
\hline Vegetable oil & Vegetable oil \\
\hline Whole grains & Maize, barley, whole-grain bread \\
\hline Nuts & $\begin{array}{l}\text { Peanuts, almonds, walnuts, pistachios, hazelnuts, } \\
\text { sunflower }\end{array}$ \\
\hline Fish & Fish \\
\hline Refined grains & White breads, baguettes, rice, spaghetti, vermicelli \\
\hline $\begin{array}{l}\text { Sweets and } \\
\text { desserts }\end{array}$ & $\begin{array}{l}\text { Biscuits, crackers, cakes and pastries, sweets, sugar, } \\
\text { honey, jam, chocolate, candy }\end{array}$ \\
\hline Solid fat & Butter, margarine, fat, animal fat \\
\hline $\begin{array}{l}\text { Red and } \\
\text { processed meat }\end{array}$ & Beef or veal, lamb, burgers, sausages \\
\hline Mayonnaise & Mayonnaise \\
\hline $\begin{array}{l}\text { High-fat dairy } \\
\text { products }\end{array}$ & $\begin{array}{l}\text { Whole milk, chocolate milk, yogurt, cream cheese, } \\
\text { cream, ice cream, curd }\end{array}$ \\
\hline Fried potato & French fries, chips \\
\hline Compote & Fruit compote \\
\hline Pickle & Pickle \\
\hline Pizza & Pizza \\
\hline Egg & Egg \\
\hline Soft drinks & Soft drinks \\
\hline Cooked potato & Cooked potato \\
\hline Tea and coffee & Tea and coffee \\
\hline Salt & Salt \\
\hline $\begin{array}{l}\text { Liver and organic } \\
\text { meat }\end{array}$ & Heart, liver and kidney \\
\hline
\end{tabular}

correlation, and a positive or negative sign shows direct or inverse relationship, respectively, between the food group and dietary pattern.

Factor loadings $<0 \cdot 3$ were retained in the analysis, but removed from the table for simplicity (Table 1 ). The normality of distribution of the data was tested using the KolmogorovSmirnov test. The variables with normal and non-normal distribution were compared using the independent $t$ and Mann-Whitney tests, respectively. The $\chi^{2}$ test was used to compare the qualitative variables between cases and controls. To assess the correlation between dietary patterns and quantitative variables with normal and non-normal distribution, Pearson's and Spearman's correlation coefficients were used, respectively. Multivariate logistic regression analysis was performed to assess the relationship between pre-diabetes and dietary patterns. Statistical significance was set at $P<0 \cdot 05$.

\section{Results}

In the present study, two dietary patterns were identified using factor analysis. The identified dietary patterns were the vegetables, fruits and legumes (VFL) dietary pattern, characterised by high intakes of vegetables, legumes, dried
Table 2. Factor loading for major dietary patterns ${ }^{\star}$

\begin{tabular}{|c|c|c|}
\hline \multirow[b]{2}{*}{ Food groups } & \multicolumn{2}{|c|}{ Dietary patterns } \\
\hline & VFL & SSMM \\
\hline Vegetables & 0.721 & \\
\hline Legumes & 0.605 & \\
\hline Dried fruit & 0.536 & \\
\hline Tomato & 0.525 & \\
\hline Fruits & 0.475 & \\
\hline Low-fat dairy products & 0.463 & \\
\hline Chicken & 0.416 & 0.348 \\
\hline Vegetable oil & 0.410 & \\
\hline Whole grains & 0.400 & \\
\hline Nuts & 0.370 & \\
\hline Fish & 0.369 & \\
\hline Refined grains & -0.311 & 0.454 \\
\hline Sweets and desserts & & 0.728 \\
\hline Solid fat & & 0.711 \\
\hline Red and processed meat & & 0.665 \\
\hline Mayonnaise & & 0.644 \\
\hline High-fat dairy products & & 0.578 \\
\hline Fried potato & & 0.526 \\
\hline Compote & & 0.459 \\
\hline Pickle & & 0.449 \\
\hline Pizza & & 0.418 \\
\hline Eggs & & 0.397 \\
\hline Soft drinks & & 0.395 \\
\hline Cooked potato & & 0.373 \\
\hline Tea and coffee & & 0.366 \\
\hline Salt & & 0.323 \\
\hline Liver and organic meat & & 0.303 \\
\hline Percentage of variance explained $\dagger$ & 11.7 & $16 \cdot 0$ \\
\hline
\end{tabular}

VFL, vegetables, fruits and legumes; SSMM, sweet, solid fat, meat and mayonnaise. *Values $<0.3$ were excluded from the table for simplicity.

†Kaiser-Meyer-Olkin measure of sampling adequacy $=0.751$. Bartlett's test of sphericity $<0.001$.

fruits, tomatoes, fruits, low-fat dairy products, chicken, vegetable oil, whole grains, nuts and fish and low intakes of refined grains, and the sweet, solid fat, meat and mayonnaise (SSMM) dietary pattern, characterised by high consumption of sweets and desserts, solid fats, red meat and processed meat, mayonnaise, high-fat dairy products, fried potato, compote, pickles, pizza, eggs, soft drinks, cooked potato, tea and coffee, salt, chicken, liver and organ meat. The factor scores were categorised as tertiles. This showed that in the VFL pattern the first tertile was less healthy, the second was moderate and the third was the healthiest. A similar interpretation was applied to the SSMM pattern. The total variance for the identified dietary patterns was $27.7 \%$ (Table 2). The general characteristics and comparison of the subjects in the case and control groups are shown in Tables 3 and 4. The mean years of education, blood pressure, FBG, 2-h OGTT, weight, WC, BMI, energy intake, the percentage of abdominal and general obesity and low physical activity were higher in subjects with pre-diabetes as compared with the control group $(P<0 \cdot 001)$. No significant difference was, however, observed between the two groups with regard to the other characteristics.

The relationship between the general characteristics and the dietary patterns is shown in Table 5. The data show that subjects in the third tertile of the VFL dietary pattern had lower weight, WC, BMI, energy intake, diastolic blood pressure, fasting blood sugar and 2-h OGTT compared with those in the 
Table 3. Characteristics of the study participants across case and control groups (Mean values and standard deviations)

\begin{tabular}{|c|c|c|c|c|c|}
\hline \multirow[b]{2}{*}{ Quantities variables } & \multicolumn{2}{|c|}{ Controls ( $n$ 150) } & \multicolumn{2}{|c|}{ Pre-diabetes ( $n$ 150) } & \multirow[b]{2}{*}{$P$} \\
\hline & Mean & SD & Mean & SD & \\
\hline Age (years) & $47 \cdot 7$ & $7 \cdot 2$ & 47.4 & 7.5 & $0.7^{\star}$ \\
\hline Education (years) & 6.9 & 3.8 & 8.9 & $4 \cdot 7$ & $<0.001^{*}$ \\
\hline Weight $(\mathrm{kg})$ & $72 \cdot 4$ & 11.4 & 77.9 & $12 \cdot 9$ & $<0.001 \dagger$ \\
\hline Height $(\mathrm{cm})$ & $162 \cdot 7$ & $9 \cdot 1$ & $163 \cdot 2$ & 8.5 & $0.5 \dagger$ \\
\hline Waist circumference $(\mathrm{cm})$ & 88.6 & 9.9 & $94 \cdot 2$ & 11.4 & $<0.001 \dagger$ \\
\hline BMI $\left(\mathrm{kg} / \mathrm{m}^{2}\right)$ & $27 \cdot 1$ & 3.6 & 29.4 & $4 \cdot 2$ & $<0.001 \dagger$ \\
\hline Energy intake (kJ/d) & $9336 \cdot 2$ & $1244 \cdot 7$ & $10138 \cdot 2$ & $1216 \cdot 3$ & $<0.001 \dagger$ \\
\hline Energy intake $(\mathrm{kcal} / \mathrm{d})$ & 2231.4 & 297.5 & 2423.1 & $290 \cdot 7$ & $<0.001 \dagger$ \\
\hline Systolic blood pressure (mmHg) & $118 \cdot 3$ & $10 \cdot 9$ & $122 \cdot 8$ & 12.5 & $<0.001^{*}$ \\
\hline Diastolic blood pressure $(\mathrm{mmHg})$ & 73.4 & $7 \cdot 7$ & 78.6 & 10.5 & $<0.001^{*}$ \\
\hline Fasting blood glucose $(\mathrm{mmol} / \mathrm{l})$ & 4.6 & 0.39 & $6 \cdot 1$ & 0.36 & $<0.001^{*}$ \\
\hline 2-h glucose $(\mathrm{mmol} / \mathrm{l})$ & $6 \cdot 7$ & 0.53 & 8.0 & 1.0 & $<0.001^{*}$ \\
\hline
\end{tabular}

* Mann-Whitney test.

$\dagger$ Independent $t$ test.

Table 4. Characteristics of the study participants across case and control groups (Numbers and percentages)

\begin{tabular}{|c|c|c|c|c|c|}
\hline \multirow[b]{2}{*}{ Variables } & \multicolumn{2}{|c|}{ Controls ( $n$ 150) } & \multicolumn{2}{|c|}{ Pre-diabetes ( $n$ 150) } & \multirow[b]{2}{*}{$P^{*}$} \\
\hline & $n$ & $\%$ & $n$ & $\%$ & \\
\hline Sex & & & & & 0.5 \\
\hline Male & 51 & 34.0 & 51 & 34.0 & \\
\hline Female & 99 & $66 \cdot 0$ & 99 & $66 \cdot 0$ & \\
\hline Marital status & & & & & 0.2 \\
\hline Single & 11 & $7 \cdot 3$ & 5 & $3 \cdot 3$ & \\
\hline Married & 129 & $86 \cdot 0$ & 133 & $88 \cdot 7$ & \\
\hline Divorce/widow & 10 & $6 \cdot 7$ & 12 & 8.0 & \\
\hline Occupation & & & & & 0.5 \\
\hline Unemployed & 5 & 3.3 & 3 & $2 \cdot 0$ & \\
\hline House keeper & 65 & $43 \cdot 3$ & 71 & $47 \cdot 3$ & \\
\hline Worker & 10 & $6 \cdot 7$ & 9 & $6 \cdot 0$ & \\
\hline Employee & 30 & $20 \cdot 0$ & 21 & $14 \cdot 0$ & \\
\hline Retired/self-employed & 40 & $26 \cdot 7$ & 46 & $30 \cdot 7$ & \\
\hline Dietary supplement intake & & & & & 0.08 \\
\hline Yes & 20 & $13 \cdot 3$ & 30 & $20 \cdot 0$ & \\
\hline No & 130 & $86 \cdot 7$ & 120 & $80 \cdot 0$ & \\
\hline Physical activity $\dagger$ & & & & & $<0.001$ \\
\hline Low & 37 & $24 \cdot 7$ & 92 & $61 \cdot 3$ & \\
\hline Moderate & 91 & $60 \cdot 7$ & 42 & $28 \cdot 0$ & \\
\hline High & 22 & $14 \cdot 7$ & 16 & $10 \cdot 7$ & \\
\hline BMI $\left(\mathrm{kg} / \mathrm{m}^{2}\right)$ & & & & & $<0.001$ \\
\hline$<25$ & 43 & $28 \cdot 7$ & 20 & $13 \cdot 4$ & \\
\hline $25-29.9$ & 81 & $54 \cdot 0$ & 65 & $43 \cdot 3$ & \\
\hline$\geq 30$ & 26 & $17 \cdot 3$ & 65 & 43.3 & \\
\hline Waist circumference $(\mathrm{cm})$ & & & & & $<0.001$ \\
\hline$<80$ women to $<90$ men & 43 & $28 \cdot 6$ & 19 & $12 \cdot 6$ & \\
\hline$\geq 80$ women to $\geq 90$ men & 107 & 71.4 & 131 & 87.4 & \\
\hline
\end{tabular}

MET, metabolic equivalent.

${ }^{*} \chi^{2}$ test.

† <600 MET/h per week: 'low', 600-3000 MET/h per week: 'moderate', >3000 MET/h per week: 'high'.

first tertile. Furthermore, those in the third tertile of the SSMM dietary pattern were found to have higher educational level, weight, WC, BMI, systolic and diastolic blood pressures, FBG and 2-h OGTT compared with those in the lowest tertile. The VFL dietary pattern score negatively correlated with weight, WC, BMI, energy intake, diastolic blood pressure, FBG and 2-h OGTT $(P<0.03)$. The SSMM dietary pattern score positively correlated with education, weight, WC, BMI, systolic and diastolic blood pressures, FBG and 2-h OGTT $(P<0 \cdot 002)$.
The OR for pre-diabetes across dietary patterns are shown in Table 6. The scores of the VFL dietary pattern were associated with lower pre-diabetes morbidity (OR 0.16; 95\% CI 0·10, 0.25). After adjusting for age, education, physical activity, BMI and energy intake in model 3, the relationship remained significant (OR $0 \cdot 16$; $95 \%$ CI $0 \cdot 10,0 \cdot 26$ ). The OR of pre-diabetes was positively associated with the SSMM dietary pattern (OR 3.01; $95 \%$ CI $2 \cdot 13$, 4.26), and the OR was found to be higher even after controlling for possible confounding variables (OR 5.45; $95 \%$ CI 3.22, 9.23). 


\section{Discussion}

In this study, the association between dietary patterns and prediabetes morbidity was investigated. The results show that the VFL and SSMM dietary patterns were inversely and directly related to pre-diabetes morbidity, respectively. In addition, the VFL dietary pattern was inversely related to weight, WC, BMI, energy intake, diastolic blood pressure, FBG and 2-h OGTT. Furthermore, the SSMM dietary pattern was positively associated with weight, WC, BMI, systolic and diastolic blood pressures, FBG and 2-h OGTT.

In a study on women in Tehran, the results showed that Healthy and Western dietary patterns were inversely and positively related to insulin resistance, respectively ${ }^{(25)}$. A study on Japanese men also found that a dietary pattern high in dairy products, fruits, vegetables and starch and low in alcohol was related to a lower risk of IGT. However, those who followed the Japanese dietary pattern, which is characterised by high intakes of soyabeans, green tea, sea alga, pickles, vegetables and fish, were found to have high risk of IGT. Meanwhile, in other studies, some of the food items found in the Japanese dietary pattern were also reported in Healthy dietary patterns, and therefore further studies are suggested to clarify the relationship between Japanese dietary patterns and pre-diabetes in the Japanese population ${ }^{(15)}$. In a study conducted in China, IGT was highly associated with the New Affluence dietary pattern. Subjects following this dietary pattern had certain lifestyle and food intake patterns, such as living in urban areas, had lower physical activity, were overweight and had higher intakes of animal food and soyabeans ${ }^{(16)}$.

A meta-analysis of ten large prospective studies showed that adherence to a Healthy dietary pattern was associated with reduced risk of developing type 2 diabetes $^{(26)}$. Dietary patterns characterised by high consumption of fruits and vegetables, whole grains, fish and poultry and low consumption of red meat, processed foods, sugar-sweetened beverages and starchy foods may retard the progression of type 2 diabetes ${ }^{(26)}$. In a study on type 2 diabetic patients, the results showed that dietary recommendations such as higher intakes of vegetables, nuts for snacks, fruits instead of juices, whole grains instead of processed cereals, legumes instead of potatoes and increased physical activity can provide long-term, sustained weight loss ${ }^{(27)}$. The results of another study on middle-aged subjects with IGT showed that intensive dietary intervention for reducing dietary total fat and SFA, and therefore an increase in dietary fibre, can prevent type 2 diabetes $^{(28)}$. In addition, the Mediterranean diet has been shown to be effective in the prevention of diabetes incidence in subjects with high cardiovascular disease risk ${ }^{(29)}$.

The dietary patterns found in the present study are similar to those found in diabetic and healthy subjects in $\operatorname{Iran}^{(23,25,30)}$. The VFL dietary pattern found in the present study is also similar to the Healthy dietary patterns of other studies ${ }^{(15,26)}$ However, dietary patterns are only comparable when similar categorisations of food groups have been used and similar patterns of factor loadings have been found. The total variance for the identified dietary pattern in this study was $27.7 \%$, which is almost similar to the total variance of other studies ${ }^{(19,23,25,31)}$. 
Table 6. Association between dietary patterns and pre-diabetes morbidity (Odds ratios and $95 \%$ confidence intervals)

\begin{tabular}{|c|c|c|c|c|c|c|c|c|}
\hline & \multicolumn{8}{|c|}{ Dietary patterns } \\
\hline & \multicolumn{4}{|c|}{ VFL } & \multicolumn{4}{|c|}{ SSMM } \\
\hline & $n$ & OR & $95 \% \mathrm{Cl}$ & $P$ & $n$ & OR & $95 \% \mathrm{Cl}$ & $P^{*}$ \\
\hline Model $1 \dagger$ & 300 & 0.16 & $0.10,0.25$ & $<0.001$ & 300 & 3.01 & $2 \cdot 13,4 \cdot 26$ & $<0.001$ \\
\hline Model $2 \ddagger$ & 300 & 0.15 & $0.10,0.25$ & $<0.001$ & 300 & 2.56 & $1.76,3.74$ & $<0.001$ \\
\hline Model 3§ & 300 & 0.16 & $0.10,0.26$ & $<0.001$ & 300 & 5.45 & $3.22,9.23$ & $<0.001$ \\
\hline
\end{tabular}

VFL, vegetables, fruits and legumes; SSMM, sweet, solid fat, meat and mayonnaise.

${ }^{*}$ Multivariate logistic regression analysis.

t Crude model.

$\ddagger$ Adjusted for age, education, physical activity and BMI.

$\S$ Additionally adjusted for energy intake.

It has been reported that healthy diets with high intakes of vegetables, vegetable oil, fish, fruits and nuts have food compounds or nutrients such as fibre, vitamins and minerals, which may decrease diabetes through a decrease in inflammation, improved metabolism of glucose and endothelial function, and sensitivity to insulin ${ }^{(12,32)}$.

The positive relationship found between the SSMM dietary pattern and pre-diabetes could be a result of low intakes of healthy foods such as fruits and vegetables and high intakes of foods such as red meat, processed meat and animal fat. The identified dietary patterns high in red meat and processed meat have been related to diabetes morbidity ${ }^{(33-35)}$. Processed meat contains a lot of salt and nitrite; moreover, a decrease in insulin action with higher $\mathrm{Na}$ intake has been reported ${ }^{(36)}$. Nitrite changes to nitrous amine, which is poisonous to the $\beta$ cells of the pancreas, and leads to insulin resistance and glucose intolerance $^{(35)}$. In addition, meat is an important source of SFA. High intake of SFA has been shown to be associated with high risk of pre-diabetes and glucose intolerance ${ }^{(37)}$. In this study, the low dietary fibre intake observed in the SSMM dietary pattern could have also played a role in the risk of pre-diabetes, as studies have shown that dietary patterns high in fibre (specially fibre of grains) protect against diabetes ${ }^{(38)}$. The high intake of whole grains, legumes, vegetables and fruits containing high fibre, owing to their low energy content and high satiety effect, may decrease food intake and weight gain ${ }^{(38)}$. However, the inverse relationship between fibre and risk of diabetes is not clear. It seems that viscose fibre lowers the speed of gastric evacuation and absorption in the small intestine ${ }^{(32,38)}$.

In the present study, the SSMM dietary pattern was observed to be characterised by high consumption of cooked potatoes, refined grains, sweets and desserts. These foods seem to have high glycaemic indices and their load could be of concern. There are reports of a direct relationship between glycaemic load and type 2 diabetes ${ }^{(39)}$, and although the exact mechanism is not clear there are some suggested approaches. High amounts of carbohydrate with high glycaemic load have been reported to increase the glucose level of the blood and the demand for insulin. Besides, high demand for insulin has been demonstrated to have some effects on the pancreas and could gradually lead to glucose intolerance ${ }^{(39)}$. Several studies have shown the relationship between sweets and sugar intake and risk of type 2 diabetes ${ }^{(40)}$. It has been reported that high intakes of refined sugar and sweet drinks with high glycaemic load could lead to an increase in weight gain, which can affect the metabolism of glucose and sensitivity to insulin, and could eventually increase the risk of diabetes ${ }^{(38)}$. In this study, tea, coffee and mayonnaise were included in the SSMM dietary pattern, although some studies have shown that the consumption of tea and coffee has protective effect on diabetes ${ }^{(41)}$; however, in some other studies, both featured in Unhealthy dietary patterns ${ }^{(23,25)}$, and this might be because of the intake of sugar and sweets along with tea or coffee. Mayonnaise has high-fat, creamy sauce ${ }^{(42)}$, and in some studies it features in the Western dietary pattern ${ }^{(25,31,42)}$. In this study, chicken was included in both dietary patterns, which might be attributed to its high consumption in Iran.

Furthermore, in this study, the mean education level was higher in pre-diabetic subjects compared with the control participants. In a study in Bangladesh, the results showed that high education level was positively related to the risk of both diabetes and pre-diabetes ${ }^{(43)}$. It has been reported that education and wealth increases the risk of obesity ${ }^{(44)}$, which is a risk factor for pre-diabetes ${ }^{(45)}$. However, several studies in Iran ${ }^{(46-48)}$, Spain ${ }^{(49)}$ and the USA ${ }^{(50)}$ have found an inverse association between diabetes morbidity and level of education. Therefore, further investigation is required in this regard.

The present study has some limitations. First and foremost, the dietary patterns were obtained from food intake patterns using a validated FFQ, although food consumption behaviours such as pattern, time, number of meals and ways of preparing the food are also important ${ }^{(51)}$. Second, a questionnaire was used to collect dietary information and as such there is the possibility of error because the information collected depends largely on recall. Third, despite the fact that pre-diabetes subjects were asked to report their dietary intake of the year before the diagnosis of pre-diabetes, they would have received dietary advice after diagnosis, which might affect their dietary responses. Fourth, factor analysis was used to identify the dietary patterns, and as such food categorisation usually can change on the basis of the researchers' interest. Fifth, although pre-diabetes was not observed in the controls, they were referred to our centre because of the existence of some criteria such as being overweight or obese, having a family history of diabetes or existence of at least two symptoms of diabetes. Thus, the comparison between pre-diabetics and controls could 
potentially not reflect a comparison between cases and true controls. Sixth, similar to all case-control studies, this study could not determine the temporal relationship between dietary patterns and pre-diabetes. However, despite the aforementioned limitations, the present study is one of the few studies that have examined the relationship between dietary patterns and risk of pre-diabetes using a case-control study design.

In conclusion, the VFL and SSMM dietary patterns are inversely and directly related to pre-diabetic morbidity, respectively. In addition, the VFL dietary pattern is associated with risk of obesity and hypertension, which are implicated in impaired glucose metabolism and development of diabetes and CVD. Future studies are therefore needed to confirm our findings with other populations.

\section{Acknowledgements}

The authors sincerely express their appreciation to the participants of this study.

This research project was supported by Tehran University of Medical Sciences (TUMS) (grant no. 93-454-76). TUMS had no role in the design, analysis or writing of this article.

G. S. and F. S. conceived and developed the idea for the study and revised the manuscript; F. B., O. M. S. and Parvaneh Yavari contributed to data collection. F. B. wrote numerous drafts of the manuscript; B. M., Mostafa Qorbani and F. K. contributed to data analysis and interpretation of the data.

There are no conflicts of interest.

\section{References}

1. Nathan DM, Davidson MB, DeFronzo RA, et al. (2007) Impaired fasting glucose and impaired glucose tolerance implications for care. Diabetes Care 30, 753-759.

2. American Diabetes Association (2010) Diagnosis and classification of diabetes mellitus. Diabetes Care 33, 62-69.

3. Eldin WS, Emara M \& Shoker A (2008) Prediabetes: a must to recognise disease state. Int J Clin Pract 62, 642-648.

4. Hsueh WA, Orloski L \& Wyne K (2010) Prediabetes: the importance of early identification and intervention. Postgrad Med 122, 129-143.

5. Al-Sinani S, Al-Shafaee M, Al-Mamari A, et al. (2014) Impaired fasting glucose in Omani adults with no family history of type 2 diabetes. Sultan Qaboos Univ Med J 14, 183-189.

6. Middelbeek RJ \& Abrahamson MJ (2014) Diabetes, prediabetes, and glycemic control in the United States: challenges and opportunities. Ann Intern Med 160, 572-573.

7. Esteghamati A, Gouya MM, Abbasi M, et al. (2008) Prevalence of diabetes and impaired fasting glucose in the adult population of Iran National Survey of Risk factors for NonCommunicable Diseases of Iran. Diabetes Care 31, 96-98.

8. Whiting DR, Guariguata L \& Weil C (2011) IDF diabetes atlas: global estimates of the prevalence of diabetes for 2011 and 2030. Diabetes Res Clin Pract 94, 311-321.

9. Yoon K-H, Lee JH, Kim JW, et al. (2006) Epidemic obesity and type 2 diabetes in Asia. Lancet 368, 1681-1688.

10. Lindström J, Ilanne-Parikka P, Peltonen M, et al. (2006) Sustained reduction in the incidence of type 2 diabetes by lifestyle intervention: follow-up of the Finnish diabetes prevention study. Lancet 368, 1673-1679.
11. Li G, Zhang P, Wang J, et al. (2008) The long-term effect of lifestyle interventions to prevent diabetes in the China Da Qing diabetes prevention study: a 20 -year follow-up study. Lancet 371, 1783-1789.

12. Feskens EJ, Virtanen SM, Rasanen L, et al. (1995) Dietary factors determining diabetes and impaired glucose tolerance: a 20-year follow-up of the Finnish and Dutch cohorts of the seven countries study. Diabetes Care 18, 1104-1112.

13. Hu FB (2002) Dietary pattern analysis: a new direction in nutritional epidemiology. Curr Opin Lipidol 13, 3-9.

14. Maghsoudi Z \& Azadbakht L (2012) How dietary patterns could have a role in prevention, progression, or management of diabetes mellitus? Review on the current evidence. J Res Med Sci 17, 694.

15. Mizoue T, Yamaji T, Tabata S, et al. (2006) Dietary patterns and glucose tolerance abnormalities in Japanese men. $J$ Nutr 136, 1352-1358.

16. He Y, Ma G, Zhai F, et al. (2009) Dietary patterns and glucose tolerance abnormalities in Chinese adults. Diabetes Care 32, 1972-1976.

17. Amini M, Shafaeizadeh S, Zare M, et al. (2012) A cross-sectional study on food patterns and adiposity among individuals with abnormal glucose homeostasis. Arch Iran Med 15, 131.

18. Rezazadeh A, Rashidkhani B \& Omidvar N (2010) Association of major dietary patterns with socioeconomic and lifestyle factors of adult women living in Tehran, Iran. Nutrition 26, 337-341.

19. Esmaillzadeh A \& Azadbakht L (2008) Major dietary patterns in relation to general obesity and central adiposity among Iranian women. J Nutr 138, 358-363.

20. International Diabetes Federation (2006) The IDF consensus worldwide definition of the metabolic syndrome. www.idf.org (accessed December 2013).

21. International Physical Activity Questionnaire Research Committee (2005) Guidelines for data processing and analysis of the International Physical Activity Questionnaire (IPAQ) - short and long forms. www.ipaq.ki.se (accessed September 2008).

22. Azadbakht L \& Esmaillzadeh A (2012) Macro and micronutrients intake, food groups consumption and dietary habits among female students in Isfahan University of Medical Sciences. Iran Red Crescent Med J 14, 204-209.

23. Zarodi M, Mirmiran P, Fazel Tabar A, et al. (2013) The association between major dietary pattern and diabetes type 2 . Health Sys Res Nutrition Supplement, 679-695 (In Persian).

24. Jackson JE (1995) Statistical factor analysis and related methods: theory and applications. Technometrics 37, 226-228.

25. Esmaillzadeh A, Kimiagar M, Mehrabi Y, et al. (2007) Dietary patterns, insulin resistance, and prevalence of the metabolic syndrome in women. Am J Clin Nutr 85, 910-918.

26. Esposito K, Kastorini C-M, Panagiotakos DB, et al. (2010) Prevention of type 2 diabetes by dietary patterns: a systematic review of prospective studies and meta-analysis. Metab Syndr Relat Disord 8, 471-476.

27. García de la Torre N, del Valle L, Durán A, et al. (2014) Dietary pattern and weight loss in new-onset type 2 diabetes mellitus: a sub-analysis of the St Carlos study: a 3-year, randomized, clinic-based, interventional study. Br J Med Med Res 4, 56675677.

28. Lindström J, Louheranta A, Mannelin M, et al. (2003) The Finnish Diabetes Prevention Study (DPS): lifestyle intervention and 3-year results on diet and physical activity. Diabetes Care 26, 3230-3236.

29. Salas-Salvadó J, Bullo M, Babio N, et al. (2011) Reduction in the incidence of type 2 diabetes with the Mediterranean diet results of the PREDIMED-Reus nutrition intervention randomized trial. Diabetes Care 34, 14-19. 
30. Rezazadeh A \& Rashidkhani B (2010) The association of general and central obesity with major dietary patterns in adult women living in Tehran, Iran. ARYA Atheroscler 6, 23-30.

31. Amini M (2012) A cross-sectional study on food patterns and adiposity among individuals with abnormal glucose homeostasis. Arch Iran Med 15, 131-135.

32. Hu FB, Van Dam R \& Liu S (2001) Diet and risk of type II diabetes: the role of types of fat and carbohydrate. Diabetologia 44, 805-817.

33. Micha R, Wallace SK \& Mozaffarian D (2010) Red and processed meat consumption and risk of incident coronary heart disease, stroke, and diabetes mellitus: a systematic review and meta-analysis. Circulation 121, 2271-2283.

34. Pan A, Sun Q, Bernstein AM, et al. (2011) Red meat consumption and risk of type 2 diabetes: 3 cohorts of US adults and an updated meta-analysis. Am J Clin Nutr 94, 1088-1096.

35. Aune D, Ursin G \& Veierød M (2009) Meat consumption and the risk of type 2 diabetes: a systematic review and metaanalysis of cohort studies. Diabetologia 52, 2277-2287.

36. Donovan DS, Solomon CG, Seely EW, et al. (1993) Effect of sodium intake on insulin sensitivity. Am J Physiol Endocrinol Metab 264, E730-E734.

37. Thanopoulou AC, Karamanos BG, Angelico FV, et al. (2003) Dietary fat intake as risk factor for the development of diabetes multinational, multicenter study of the Mediterranean Group for the Study of Diabetes (MGSD). Diabetes Care 26, 302-307.

38. Al-Khudairy L, Stranges S, Kumar S, et al. (2013) Dietary factors and type 2 diabetes in the Middle East: what is the evidence for an association? - a systematic review. Nutrients 5, 3871-3897.

39. Schulze MB, Liu S, Rimm EB, et al. (2004) Glycemic index, glycemic load, and dietary fiber intake and incidence of type 2 diabetes in younger and middle-aged women. Am J Clin Nutr 80, 348-356.

40. Kastorini C-M \& Panagiotakos DB (2009) Dietary patterns and prevention of type 2 diabetes: from research to clinical practice; a systematic review. Curr Diabetes Rev 5, 221-227.
41. Salazar-Martinez E, Willet WC, Ascherio A, et al. (2004) Coffee consumption and risk for type 2 diabetes mellitus. Ann Intern Med 140, 1-8.

42. Hu FB, Rimm E, Smith-Warner SA, et al. (1999) Reproducibility and validity of dietary patterns assessed with a foodfrequency questionnaire. Am J Clin Nutr 69, 243-249.

43. Akter S, Rahman MM, Abe SK, et al. (2014) Prevalence of diabetes and prediabetes and their risk factors among Bangladeshi adults: a nationwide survey. Bull World Health Organ 92, 204-213, 213A.

44. Monteiro CA, Conde WL \& Popkin BM (2001) Independent effects of income and education on the risk of obesity in the Brazilian adult population. J Nutr 131, 881S-886S.

45. Al-Shafaee MA, Bhargava K, Al-Farsi YM, et al. (2011) Prevalence of pre-diabetes and associated risk factors in an adult Omani population. Int J Diabetes Dev Ctries 31, $166-173$.

46. Harati H, Hadaegh F, Saadat N, et al. (2009) Population-based incidence of type 2 diabetes and its associated risk factors: results from a six-year cohort study in Iran. BMC Public Health 9, 186.

47. Azimi-Nezhad M, Ghayour-Mobarhan M, Parizadeh MR, et al. (2008) Prevalence of type 2 diabetes mellitus in Iran and its relationship with gender, urbanisation, education, marital status and occupation. Singapore Med J 49, 571-576.

48. Golozar A, Khademi H, Kamangar F, et al. (2011) Diabetes mellitus and its correlates in an Iranian adult population. PLOS ONE 6, 26725.

49. Soriguer F, Goday A, Bosch-Comas A, et al. (2012) Prevalence of diabetes mellitus and impaired glucose regulation in Spain: the Di@bet.es study. Diabetologia 55, 88-93.

50. Borrell LN, Dallo FJ \& White K (2006) Education and diabetes in a racially and ethnically diverse population. Am J Public Health 96, 1637-1642.

51. Tseng M (1999) Validation of dietary patterns assessed with a food-frequency questionnaire. Am J Clin Nutr 70, 422. 